\title{
Eskişehir İli Mera Alanlarında Bulunan Bitkilerin IUCN Tehdit Kategorilerine Göre Değişen Durumları
}

${ }^{*}$ Celalettin AYGÜN İsmail KARA
İlker ERDOĞDU

Geçit Kuşağı Tarımsal Araştırma Enstitüsü Müdürlüğü, Eskişehir

*Sorumlu yazar e-posta (Corresponding author; e-mail): aydadas@gmail.com

Geliş Tarihi (Received): 01.04.2015
Kabul Tarihi (Accepted): 04.06.2015

\section{Öz}

Bu çalışmada, Eskişehir ilinde 2007-2008 yılları arasında 143 mera alanında Modifiye Edilmiş Tekerlekli Nokta metodu ile yapılan vejetasyon etüdü sonucunda belirlenen bitkilerin The International Union for Conservation of Nature (IUCN) tehdit kategorilerine göre durumlarının belirlenmesi amaçlanmıştır. Eskişehir ili mera alanlarında Türkiye Bitkileri Kırmızı Kitabı esas alınarak bitkilerin 1989 ve 2000 yıllarındaki tehdit kategorilerine göre durumları karşılaştırılmasında; 1989 yılındaki durumları; Tehlike altında olan (E) bir tür, nadir kategorisinde $(R) 23$ tür, Yetersiz kategorisinde ise $(K) 1$ tür ve listede yok n/l = 4 tür, 2000 yılındaki durumlarında ise; Vahim kategorisinde (CR) 1 tür, Tehlike kategorisinde (EN) 2 tür, Zarar görebilir(VU) kategorisinde 11 tür, Az Tehdit Altında (LR) kategorisinde 12 tür ve n/l kategorisinde 8 tür belirlenmiştir. 1989 ve 2000 yıllarındaki durumları karşılaştırıldığında Tehlikede (E) olan bir türün n/l durumunu aldığı, zarar görebilir (V) kategorisinde olan 5 türden 1 tanesinin Tehlikede (EN), bir tanesinin $\mathrm{n} / \mathrm{l}$ durumunda, bir tanesinin az tehdit altında (LR), bir türün çok tehlikede (CR), bir türün ise zarar görebilir (VU) durumuna geçtiği, Nadir (R) kategorisinde olan 21 türden 11 türün az tehdit altında (LR), 3 türün n/l durumuna, 7 türün zarar görebilir (VU), Yetersiz (K) kategorisindeki bir türün Tehlikede (EN) kategorisine geçtiği, n/l durumunda olan dört türden ikisinin aynı kaldığı, iki türün ise zarar görebilir (VU) kategorinde bulunduğu, 2013 yılı endemikler listesinde ise; 4 türün tehdide yakın (NT), 5 türün asgari endişe (LC), bir türün ise zarar görebilir (VU), 2015 IUCN taramasında ise bir türün düşük riskli (LC), durumunda olduğu belirlenmiştir.

Anahtar Kelimeler: Eskişehir, mera, IUCN kategori, tehdit

\section{Varying IUCN Threat Categories of the Plants of Eskişehir Province Grasslands}

\begin{abstract}
This study was aimed to determine growing condition of plants according to threat categories as a result of vegetation study made by modified Wheel point method in area of 143 in Eskişehir province in comparison of plants based on Redbook of Turkey's plant groving in Eskişehir pasture areas. Growing conditions of plants in 1989 and 2000 determined are below; in 1989; 1 specie (E) endangered, 23 species $(\mathrm{R})$ rare, 1 specie $(K)$ deficient and 4 species $(n / l)$ not in the list. In 2000; 1 specie (CR) critically endangered, 2 species (EN) endangered, 11 species (VU) vulnerable, 12 species (LR) least threatened, 8 species (n/l) not in the list. In comparison of 1989 and 2000 changes occurred in plant growing conditions and changes occurred are shown below; 1 species from (E) endangered to $(n / l)$ not in the list, in 5 species in $(\mathrm{V})$ vulnerable 1 to $(\mathrm{EN})$ endangered, 1 to $(\mathrm{n} / \mathrm{l})$ not in the list, 1 to $(\mathrm{CR})$ critically endangered and last one to (VU) susceptible of 21 species in (R) rare 11 species to (LR) least threatened, 3 species to $(n / l)$ not in the list and 7 species to (VU) susceptible. One species in (K) deficient changed to (EN) endangered. Besides 4 species remained same growing conditions and 2 species were found as (VU) vulnerable, in the endemics list 4 species(NT) near threatened, 5 species (LC) least concern, 1 species (VU) vulnerable and 2015 IUCN browse; 1 species (LC) least concern were determined.
\end{abstract}

Keywords: Eskişehir, grassland, IUCN category, threat. 


\section{Giriş}

Ü Ikemizdeki floristik zenginlikleri içerisinde yer alan mera bitkilerinin mevcudiyetlerinin sürdürülebilirliği önemli olup, bu zenginliğin IUCN kriterlerine göre durumlarının belirlenmesi, meraların kullanılması ve ıslah çalışmaları esnasında dikkate alınması amacıyla ortaya konulmaya çalışıımıştır. İnsan aktiviteleri dünyayı biyotik krizin eşiğine getirmiş olup, birçok biyolog önümüzdeki on yıllarda türlerin çoğunun kaybolacağını düşünmektedirler (Ehrlich ve Wilson 1991; Wilson 1992). Daha az bilim adamı ise uzun dönemde bu yok oluşların sadece biyolojik çeşitliliğin değil evrimsel süreçleri de oluşturduğunu bildirmişlerdir (Mayers, ve Andrew., 2000). Dolaysisıyla mevcut ve öngörülen çevresel tedirginlikler evrimin mirası ve geleceği gibi iki önemli konuyu içine aldığı bildirilmektedir (Ehrlich ve ark. 1991;Wilson 1992).

Gezegenimiz üzerindeki biyotik krizin bitki türlerinin büyük bir çoğunluğunu yok olma tehlikesi ile karşı karşıya bıraktığı çok iyi bilinmekle birlikte bu krizin uzun dönemde çok önemli muhtemel sonuçları ile milyonlarca yıl boyunca devam ederek evrimin temel işlevlerini ve süreçlerini bozarak tüketeceği bildirilmektedir (Mayers, ve Andrew., 2000). Ulusal biyolojik çeşitlilik stratejisi eylem planında (UBSEP 1999) Türkiye ekosistemlerini, BM biyolojik çeşitlilik sözleşmesi tarafından belirlenen ekosistem tiplerine göre 6 tematik alana bölmekte, başka deyişle Türkiye'yi tarım, orman, dağ, step, sulak alan, kıyı ve deniz ekosistemlerine ve bu ekosistemlerin farklı formlarına ve farklı kombinasyonlarına sahiptir (UBSEP 1999).

$\mathrm{Bu}$ manada mera ekosistemlerinin dünyadaki karaların yaklaşık $\% 50$ 'sini kapladığı, küresel olarak evcil hayvanların yem intiyacının takriben \%70 'ini sağladığı (Brown ve Thorpe 2008), dünyadaki tarım yapılan alanların 1.382 milyar ha. ile toplam alanın $\% 10,8$ 'ine karşılık gelirken, sadece otlatılarak değerlendirilen gerçek doğal meraların yaklaşık 3.357 milyar ha ile \%26,0 alan kapladığı, bu durumun ülkemiz yüzölçümünün (\%18,8;14.616.687 ha.) oranı ile geniş yer kaplamakta olup, Orta Anadolu bölgesinde ise 4.902.000 ha. $(\% 24,8)$ ikinci sırada yer almaktadır (Altın ve ark. 2011). Çayır mera alanı Eskişehir'de ise 325.851 ha. (\%6) olarak belirlenmiştir (Anonim 2011).
Dünya, Olsen Global Ecosystem sınıflandırılmasına göre oluşturulan haritalamada küresel arazi örtüsü özelliklerine göre meraları sekiz sınıfta değerlendirmiş, kapalı çalııklar, açık çalılıklar, odunsuların yer aldığı savanlar, meralar, tundralar, otlak dışı alanlar olarak belirtilmiştir (White ve ark. 2000; Loveland ve ark., 2000; GLCCD.,2000; Mayers, ve Andrew., 2000).

Ülkemizin tarım, orman, dağ, step, sulak alan, kıyı ve deniz ekosistemlerine ve bu ekosistemlerin farklı formlarına ve farklı kombinasyonlarına sahip olduğu bildirilmiştir (Atalay 2002; Avcı 2005).

Eskişehir ili Davis (1988) kareleme sistemine göre A3, B3 ve B4 kareleri içerisinde, İran-Turan flora bölgesinde yer almakta olup, 12 homojen ekolojik alanın bulunduğu, yıllık ortalama yağış $373,8 \mathrm{~mm}$. dir. İlin toplam yüzölçümünün 1.365 .200 ha olup, bunun (\%42.6; 582.505 ha)'ık kısmı işlenen tarım arazisi, ormanlık ve fundalık alanlar (\%24.2; 331.263 ha.) mera alanlarının oranı ise $(\% 23.9 ; 325.851$ ha.) olarak dağılım göstermektedir ( Anonim 2011).

\section{Materyal ve Yöntem}

Projenin materyalini, Türkiye Bilimsel ve Teknolojik Araştırma Kurumu tarafından desteklenen "Ulusal Mera Kullanım ve Yönetim Projesi" dâhilinde Eskişehir ili meralarında tespit edilen azalıcı, çoğalıcı, istilacı ve diğer bitkilerin IUCN tehdit kategorilerine göre 2013 yılında değerlendirilen bitkiler oluşturmuştur.

Vejetasyon etüdü için durak sayısı ve koordinatlarının belirlenmesi amacıyla nispeten homojen ekolojik alanlar haritası kullanılmış Yıldız ve ark. (2009), çalışılacak alanı temsil edecek yeterli sayıda durakların koordinatları belirlenerek yer verilerinin alınması için küresel konumlama sistemi (GPS) cihazı ve eğim ölçer kullanılmıştır. Etüt alanlarının arazide doğrulaması yapılarak etütler gerçekleştirilmiştir.

Mera vejetasyon etütleri, izleme ve değerlendirme çalışmaları bu doğal kaynakların yaygın olduğu birçok ülkelerde yapılmakta olup, meraların mülkiyet durumları ve yönetim biçimlerine göre uygulanan yöntemlerde de farklıııklar ortaya çıkmaktadır. Doğal ve yarı doğal meralarda uygulanan 
yöntemler bir birine benzerlik göstermekte, geniş alanlarda çalışmaları hızlandırmak ve iş verimliliğini artırmak üzere bilinen yöntemlerde bazı uyarlamalar yapılmaktadır. Çalışılan alanda botanik kompozisyonu belirlemek için nokta çerçeve metodunun modifiye edilmiş şekli olan, ilk önce (Tidmarsh ve Havenga 1955) tarafından kullanılan tekerlekli nokta yöntemi daha sonra Griffin (1989) tarafından geliştirilmiş ve Koç ve Çakal (2004) tarafından açıklanan modifiye edilmiş tekerlek nokta metodu kullanılmıştır.
$\mathrm{Bu}$ metotta vejetasyon etüdü meradaki hâkim bitkilerin çiçeklendiği dönemde doğu, batı, kuzey ve güney yöneyleri esas alınarak 4 hatta toplam 400 noktada bitki okunmak suretiyle yapılmıştır. Okuma yapılırken lup içerisinde okunan her bir bitki türüne ait değerler toplam bitki sayısına oranlanarak türlerin botanik kompozisyondaki oranları tespit edilmiş, lup içerisine bitki düşmüyorsa ya da taş ise çıplak alan olarak değerlendirilmiş (Gökkuş ve ark. 1995)'a göre bitki frekansı hesaplanmıştır.

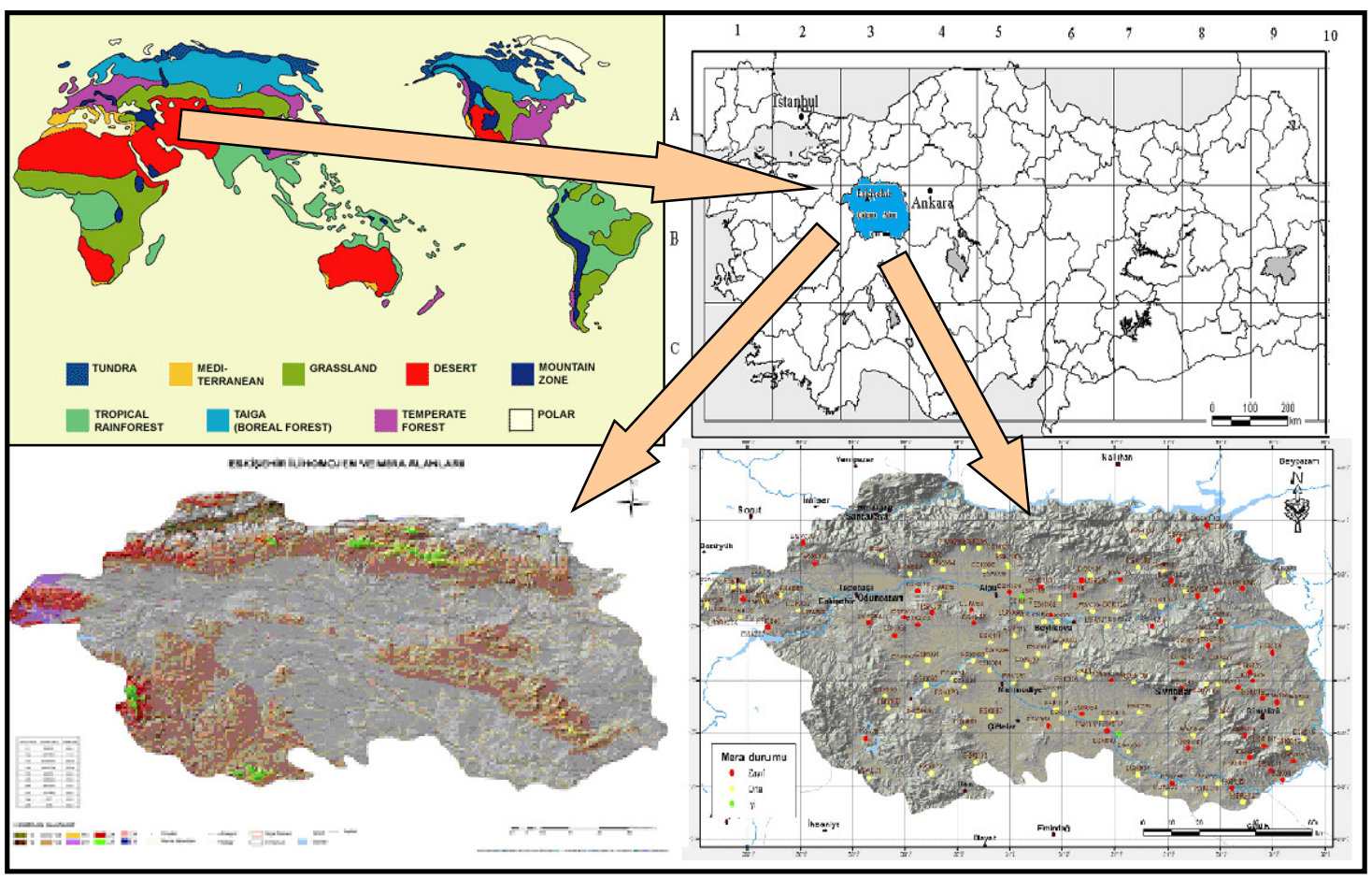

Şekil 1. Eskişehir ilindeki çalışma alanı

Figure 1. Study sites in Eskişehir Province
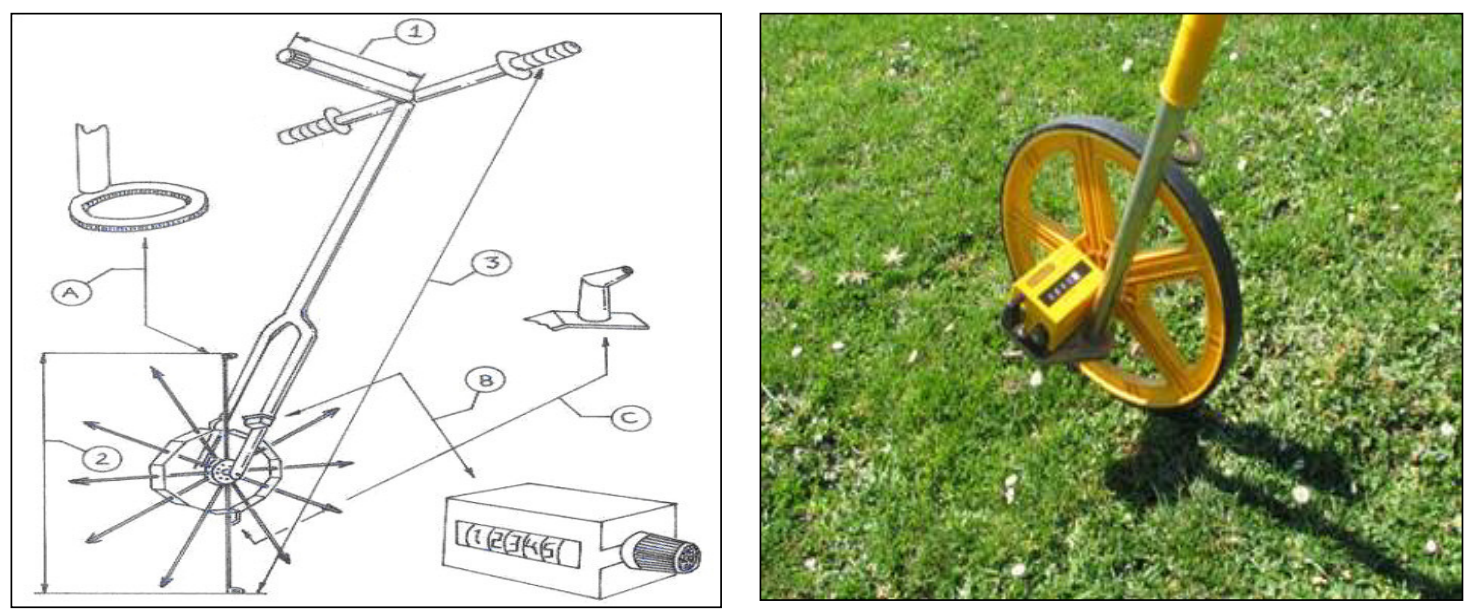

Şekil 2. Modifiye edilmiş tekerlekli nokta aleti

Figure 2. Modified Wheel-point device 


\section{Bulgular ve Tartışma}

Türkiye'nin farklı coğrafik yapılara sahip olmasına paralel olarak farklı iklim tiplerine sahip olduğu ve buna bağlı olarak da çok farklı bitki örtüsüne sahip olduğu bilinen bir gerçektir (Yıldız ve ark. 2009).Tüm Avrupa kıtasında 12.500 açık ve kapalı tohumlu bitki türü varken (Barthlott ve ark. 1999), sadece Anadolu'da bu sayıya yakın (yaklaşık 11.000) tür olduğu (Ekim ve ark. 2000; Erik ve Tarikahya 2004), bunların 3.649 (\%32) tanesinin endemik tür olması (Akgül ve ark. 2014) bunu açıkça ortaya koymaktadır. Öte yandan, ülkemizdeki bitki türlerinin büyük bir kısmı, yaklaşık 100 kadar ağaç çeşidi ve çok sayıda çalımsı ve otsu türler olarak, ormanlık alanlar kapsamında bulunduğu bildirilmiştir(Demirci 2011). Nitekim Türkiye'nin yüzeyi dünya yüzölçümünün $\% 0,5$ 'i kadar iken dünyada yaşayan bitki türlerinin $\% 2,4$ 'üne ev sahipliği yaptığı (Işık 1999) bildirilmektedir. Biyolojik çeşitlilik, örneklenen alanlar arttıkça artmakta, ekvatordan kutuplara doğru gidildikçe azalmakta ve genel olarak nemli ve sıcak bölgelerde yükselmektedir (Anonim., 2013).

Eskişehir ili mera alanlarında Türkiye bitkileri kırmızı kitabı esas alınarak bitkilerin 1989 ve 2000 yıllarındaki tehdit kategorilerine göre durumları belirlenmiş, 1989 ve 2000 yılları arasındaki değişen kategori durumları karşılaştırılmıştır. Buna ek olarak il meralarında bulunan endemiklerin tehdit durumları incelenmiştir.

Değerlendirilmeye alınan mera alanlarındaki bitkilerin ait oldukları familyalar, bitkinin etki durumu, kaç durakta bulunduğu, tek veya çok yıllık olma durumları incelenmiş olup 1989 yılındaki durumları ise tehlike altında olan $(E)$ bir tür, nadir kategorisinde $(R) 23$ tür, yetersiz kategorisinde ise $(K) 1$ tür ve listede yok kategorisinde $\mathrm{n} / \mathrm{l}=4$ tür (listede yok anlamında $\mathrm{n} / \mathrm{l}$ olarak) belirtilmiştir.

Eskişehir'de 142 durakta vejetasyon etüdü yapılmış ve 275 farklı tür tespit edilmiştir. Tespit edilen türlerin 33 adedinin (\%12,0) buğdaygil (Poaceae), 39 adedinin baklagil (Fabaceae) $(\% 14.2)$ ve 202 adedinin (\%73.7) diğer familyalara ait türler olduğu ortaya çıkmıştır. Saptanan türlerin kalite derecelerine göre dağılımına bakıldığında 21 adedinin (\%7.7) azalıcı, 20 adedinin (\%7.3) çoğalıcı ve 233 adedinin (\%85.0) istilacı türlerden oluştuğu belirlenmiştir (Aygün ve ark.,2013).
1989 ve 2000 yıllarındaki durumları karşılaştırıldığında tehlikede $(E)$ olan bir türün $\mathrm{n} / \mathrm{l}$ durumunu aldığı, zarar görebilir (V) kategorisinde olan 5 türden 1 tanesinin tehlikede $(E N)$, bir tanesinin listede yok $n / l$ durumunda, bir tanesinin az tehdit altında (LR), bir türün çok tehlikede (CR), bir türün ise zarar görebilir (VU) durumuna geçtiği, nadir(R) kategorisinde olan 21 türden 11 türün az tehdit altında(LR), 3 türün $\mathrm{n} / \mathrm{I}$ durumuna, 7 türün zarar görebilir (VU), yetersiz (K) kategorisindeki bir türün tehlikede (EN) kategorisine geçtiği, n/l durumunda olan dört türden ikisinin aynı kaldığı, iki türün ise zarar görebilir (VU) kategorinde bulunduğu belirlenmiştir.

2000 yllındaki tehlike kategorlsindeki durumlarının incelenmesinde ise; çok tehlike kategorisinde (CR) 1 tür, tehlike kategorisinde (EN) 2 tür, zarar görebilir (VU) kategorisinde 11 tür, az tehdit altında (LR) kategorisinde 12 tür ve listede yok $\mathrm{n} / \mathrm{l}$ kategorisine 8 tür belirlenmiştir.

2013 endemikler listesinde dört türün tehdide yakın (NT), 5 türün asgari endişe (LC), bir türün ise zarar görebilir (VU) kategorisinde olduğu, bitkilerin 2015 IUCN taramasında ise bir türün düşük riskli (LC), durumunda olduğu belirlenmiştir.

\section{Sonuç}

Mera alanlarını kullanırken dikkate edilmesi gereken konulardan birisi de tahribata meydan vermeden faydalanmak, biyolojik çeşitliliğin tahribatını artıran toplamalar yapmamak, mevcudu muhafaza ederek gerek biyoçeşitliliği, gerekse toprağı yerinde tutmak gereği her zaman geçerliliğini sürdürecektir. 1989 yılında durumları incelenen 32 adet bitki sayısı 2000 yıında 34 adete çıkmış, Bu bitkilerden 10 adeti 2013 endemikler listesinde yer almış, 2015 IUCN Kırmızı Listesinde ise 32 bitki tehdit kategorilerinde değerlendirilmiştir.

\section{Teşekkür}

Desteklerinden dolayı TÜBITAK (KAMAG Proje No: 106G017) teşekkürlerimizi sunarız. 
Aygün ve ark. "Eskişehir İli Mera Alanlarında Bulunan Bitkilerin IUCN Tehdit Kategorilerine Göre Değişen Durumları"

Çizelge 1. Eskişehir ili mera alanlarında bulunan bitkilerin IUCN kategorilerine göre 1989 yılı durumları Table 1. Characteristics and distribution of plants in grasslands of Eskişehir province in 1989 by IUCN category

\begin{tabular}{|c|c|c|c|c|c|}
\hline \multicolumn{6}{|c|}{ Eskişehir - 1989 Yılı Durumları } \\
\hline $\begin{array}{l}\text { Tehlike } \\
\text { Durumu }\end{array}$ & Bitki Türleri & $\begin{array}{l}\text { Durak } \\
\text { Sayısı }\end{array}$ & Etki & Familya & 1989 \\
\hline \multicolumn{6}{|c|}{$E=$ Tehlikede } \\
\hline & Erodium cicutarium (L.) & 7 & İstilacı & Geraniaceae & 1 \\
\hline \multicolumn{6}{|c|}{$\mathbf{R}=$ Nadir Biliniyor } \\
\hline & $\begin{array}{l}\text { Acantholimon acerosum (Willd.) } \\
\text { Boiss. }\end{array}$ & 36 & İstilacı & Plumbaginaceae & 1 \\
\hline & Achillea nobilisL. & 1 & İstilacı & Asteraceae & 1 \\
\hline & Ajuga chamaepitys (L.) Schreb. & 3 & İstilacı & Lamiaceae & 1 \\
\hline & Alkanna orientalis (L.) Boiss. & 4 & İstilacı & Boraginaceae & 1 \\
\hline & Alyssum pateri Nyár. & 33 & İstilacı & Brassicaceae & 1 \\
\hline & Anchusa azurea Mill. & 1 & İstilacı & Boraginaceae & 1 \\
\hline & Anthemis cretica L. & 11 & İstilacı & Asteraceae & 1 \\
\hline & Anthemis tinctoria $\mathrm{L}$. & 2 & İstilacı & Asteraceae & 1 \\
\hline & Asperula lilaciflora Boiss. & 16 & İstilacı & Rubiaceae & 1 \\
\hline & Asperula nitida $\mathrm{Sm}$. & 1 & İstilacı & Rubiaceae & 1 \\
\hline & Carduusnutans Boiss. ex Nyman & 1 & İstilacı & Asteraceae & 1 \\
\hline & $\begin{array}{l}\text { Centaurea drabifolia( DC.) } \\
\text { Wagenitz }\end{array}$ & 1 & İstilacı & Asteraceae & 1 \\
\hline & Euphorbia anacampseros Boiss. & 1 & İstilacı & Euphorbiaceae & 1 \\
\hline & Genista lydia Boiss. var. lydia & 2 & İstilacı & Fabaceae & 1 \\
\hline & $\begin{array}{l}\text { Minuartia anatolica (Boiss.) } \\
\text { Woronow }\end{array}$ & 15 & İstilacı & Caryophyllaceae & 1 \\
\hline & Nonea caspica G. & 1 & İstilacı & Boraginaceae & 1 \\
\hline & Scorzonera suberosa K.Koch & 5 & İstilacı & Asteraceae & 1 \\
\hline & Scutellaria orientalis L. & 7 & İstilacı & Lamiaceae & 1 \\
\hline & Secale cereale L. & 1 & İstilacı & Poaceae & 1 \\
\hline & Trifolium repens L. var. repens & 1 & Azalıcı & Fabaceae & 1 \\
\hline & Trigonella spinosa L. & 2 & İstilacı & Fabaceae & 1 \\
\hline & Tripleurospermum rosellum Hayek & 1 & İstilacı & Asteraceae & 1 \\
\hline & Verbascum cheiranthifolium Boiss & 7 & İstilacı & Scrophulariaceae & 1 \\
\hline \multicolumn{6}{|c|}{$\mathrm{K}=$ Yetersiz } \\
\hline & Erodium absinthoides WILLD. & 1 & İstilacı & Geraniaceae & 1 \\
\hline \multicolumn{6}{|c|}{ n/l =Listede Yok } \\
\hline & $\begin{array}{l}\text { Astragalus kochakii Aytaç } \\
\text { \&H.Duman }\end{array}$ & 2 & İstilacı & Fabaceae & 1 \\
\hline & Juniperus oxycedrus L. & 1 & İstilacı & Cupressaceae & 1 \\
\hline & Polygala pruinosa Boiss. & 1 & İstilacı & Polygalaceae & 1 \\
\hline & Bromus tomentellus Boiss. & 1 & Azalıcı & Poaceae & 1 \\
\hline
\end{tabular}

1989 yııında yayımlanan listede ki IUCN kategorilerinden indekste yer alanların sembolleri: E=Tehlikede, V= Zarar Görebilir, $\mathbf{R}=$ Nadir Bilinmiyor, $\mathbf{K}=$ Yetersiz, I: Bilinmiyor, $\mathbf{n} / \mathbf{l}=$ bilinmiyen

Legends of categories listed in IUCN in 1989 E=Endangered, $\boldsymbol{V}=$ Vulnerable, $\boldsymbol{R}=$ Rare, $\boldsymbol{K}=$ Deficient, $\mathbf{I}=$ Unknown, $\boldsymbol{n} / \mathbf{l}=$ Not on the list 
Çizelge 2. Eskişehir ili mera alanlarında bulunan bitkilerin IUCN kategorilerine göre 2000 yılı durumları

Table 2. Characteristics and distribution of plants in grasslands of Eskişehir province in 2000 by IUCN category

\begin{tabular}{|c|c|c|c|c|c|}
\hline \multicolumn{6}{|c|}{ Eskişehir 2000 Yılı Durumları } \\
\hline Etki & Bitki Türleri & $\begin{array}{l}\text { Durak } \\
\text { Sayısı }\end{array}$ & Etki & Familya & 000 \\
\hline \multicolumn{6}{|c|}{ CR = Çok Tehlikede } \\
\hline & Nepeta nuda L. & 2 & İstilacı & Lamiaceae & 1 \\
\hline \multicolumn{6}{|c|}{ EN = Tehlikede } \\
\hline & Alopecurus myosuroides Hudson. & 2 & İstilacı & Poaceae & 1 \\
\hline & Erodium absinthoides WILLD & 1 & İstilacı & Geraniaceae & 1 \\
\hline \multicolumn{6}{|c|}{ VU = Zarar Görebilir } \\
\hline & Asperula nitida Sm. & 1 & İstilacı & Rubiaceae & 1 \\
\hline & Astragalus kochakii Aytaç \&H.Duman & 2 & İstilacı & Fabaceae & 1 \\
\hline & Euphorbia anacampseros Boiss. & 1 & İstilacı & Euphorbiaceae & 1 \\
\hline & Genista lydia Boiss. var. lydia & 2 & İstilacı & Fabaceae & 1 \\
\hline & Juniperus oxycedrus L. & 1 & İstilacı & Cupressaceae & 1 \\
\hline & Minuartia anatolica (Boiss.) Woronow & 21 & İstilacı & Caryophyllaceae & 1 \\
\hline & Secale cereale $\mathrm{L}$. & 1 & İstilacı & Poaceae & 1 \\
\hline & Thymus leucostomus Hausskn. \& Velen. & 23 & İstilacı & Lamiaceae & 1 \\
\hline & Trifolium repens L. var. repens & 1 & Azalıcı & Fabaceae & 1 \\
\hline & Tripleurospermum rosellum Hayek & 1 & İstilacı & Asteraceae & 1 \\
\hline & Verbascum cheiranthifolium Boiss & 8 & İstilacı & Scrophulariaceae & 1 \\
\hline \multicolumn{6}{|c|}{ LR = Az Tehdit Altında } \\
\hline & Acantholimon acerosum (Willd.) Boiss. & 36 & İstilacı & Plumbaginaceae & 1 \\
\hline & AchilleanobilisL. & 1 & İstilacı & Asteraceae & 1 \\
\hline & Ajuga chamaepity s(L.) Schreb. & 2 & İstilacı & Lamiaceae & 1 \\
\hline & Alkanna orientalis (L.) Boiss. & 1 & İstilacı & Boraginaceae & 1 \\
\hline & Alyssum pateri Nyár. & 13 & İstilacı & Brassicaceae & 1 \\
\hline & AnthemiscreticaL. & 9 & İstilacı & Asteraceae & 1 \\
\hline & Anthemis tinctoria L. & 2 & İstilacı & Asteraceae & 1 \\
\hline & Asperula lilaciflora Boiss. & 13 & İstilacı & Rubiaceae & 1 \\
\hline & Carduus nutans Boiss. ex Nyman & 1 & İstilacı & Asteraceae & 1 \\
\hline & Centaurea drabifolia (DC.) Wagenitz & 1 & İstilacı & Asteraceae & 1 \\
\hline & Convolvulus pulvinatus Sa'ad & 1 & İstilacı & Convolvulaceae & 1 \\
\hline & Scorzonera suberosa K.Koch & 1 & İstilacı & Asteraceae & 1 \\
\hline \multicolumn{6}{|c|}{ n/l = Listede Yok } \\
\hline & Anchusa azurea Mill. & 1 & İstilacı & Boraginaceae & 1 \\
\hline & Bromus tomentellus Boiss. & 1 & Azalıcı & Poaceae & 1 \\
\hline & Centaurea hyalolepis Boiss. & 1 & İstilacı & Asteraceae & 1 \\
\hline & Erodium cicutarium(L.) L'Hér. & 4 & İstilacı & Geraniaceae & 1 \\
\hline & Nonea caspica G. & 1 & İstilacı & Boraginaceae & 1 \\
\hline & Polygala pruinosa Boiss. & 1 & İstilacı & Polygalaceae & 1 \\
\hline & Scutellaria orientalis L. & 7 & İstilacı & Lamiaceae & 1 \\
\hline & Trigonella spinosa L. & 5 & İstilacı & Fabaceae & 1 \\
\hline
\end{tabular}

2000 yılında yayımlanan ikinci listedeki yeni IUCN kategorilerinden indekste yer alanların sembolleri: Ex: Tükenmiş, CR: çok tehlikede, EN: Tehlikede, VU: Zarar görebilir, LR: Az tehdit altında, DD: Veri yetersiz, n/I = bir tür belirlenmiştir.

Legends of categories listed in IUCN in (2000) Ex: Extinct, , CR:Critically Endangered, EN: Endangered, VU: Vulnerable, LR: Least Threatened, DD: Data Deficient, $n$ /l: Not on the list 
Aygün ve ark. "Eskişehir Ili Mera Alanlarında Bulunan Bitkilerin IUCN Tehdit Kategorilerine Göre Değişen Durumları"

Çizelge 3. Eskişehir ili mera alanlarında bulunan bitkilerin IUCN kategorilerine göre1989-2000 durumlarının karşılaştırılması, 2013 endemikler listesindeki kategorileri

Table 3. Comparison of characteristics of plants grown in grasslands of Eskişehir province in 1989 and 2000 by IUCN category,. Categories of endemic plant in 2013

\begin{tabular}{|c|c|c|c|c|}
\hline Bitki Türleri & $\begin{array}{c}2013 \\
\text { Endemikler }\end{array}$ & $\begin{array}{l}\text { Tehlike } \\
\text { Durumu }\end{array}$ & $\begin{array}{c}2015 \\
\text { IUCN } \\
\text { KIrmızı } \\
\text { Liste }\end{array}$ & Familya \\
\hline Erodium cicutarium $(L)$ 'Hér. & - & $E$ & $\mathrm{n} / \mathrm{l}$ & Geraniaceae \\
\hline Alopecurus myosuroides Hudson & - & $\mathrm{V}$ & EN & Poaceae \\
\hline Centaurea hyalolepis Boiss. & - & $\mathrm{V}$ & $\mathrm{nl}$ & Asteraceae \\
\hline Convolvulus pulvinatus Sa'ad & NT & $\mathrm{V}$ & LR & Convolvulaceae \\
\hline Nepeta nuda $L$. & - & V & CR & Lamiaceae \\
\hline Thymus leucostomus Hausskn. \& Velen. & NT & $\mathrm{V}$ & VU & Lamiaceae \\
\hline Acantholimon acerosum (Willd.) Boiss. & - & $\mathrm{R}$ & LR & Plumbaginacea \\
\hline Achillea nobilis L. & - & $\mathrm{R}$ & LR & Asteraceae \\
\hline Ajuga chamaepitys (L.) Schreb. & NT & $\mathrm{R}$ & LR & Lamiaceae \\
\hline Alkanna orientalis (L.) Boiss. & - & $\mathrm{R}$ & LR & Boraginaceae \\
\hline Alyssum pateri Nyár. & LC & $\mathrm{R}$ & LR & Brassicaceae \\
\hline Anchusa azurea Mill. & - & $\mathrm{R}$ & $\mathrm{nl}$ & Boraginaceae \\
\hline Anthemis cretica L. & - & $\mathrm{R}$ & LR & Asteraceae \\
\hline Anthemis tinctoria L. & - & $\mathrm{R}$ & LR & Asteraceae \\
\hline Asperula lilaciflora Boiss. & NT & $\mathrm{R}$ & LR & Rubiaceae \\
\hline Asperula nitida Sm. & - & $\mathrm{R}$ & VU & Rubiaceae \\
\hline Carduus nutans Boiss. ex Nyman & - & $\mathrm{R}$ & LR & Asteraceae \\
\hline Centaurea drabifolia Sm. & LC & $\mathrm{R}$ & LR & Asteraceae \\
\hline Genista lydia Boiss. var. Iydia & & $\mathrm{R}$ & VU & Fabaceae \\
\hline Minuartia anatolica (Boiss.) Woronow & LC & $\mathrm{R}$ & VU & Caryophyllaceae \\
\hline Scorzonera suberosa K.Koch & LC & $\mathrm{R}$ & LR & Asteraceae \\
\hline Scutellaria orientalis L. & - & $\mathrm{R}$ & $\mathrm{nl}$ & Lamiaceae \\
\hline Secale cereale L. & - & $\mathrm{R}$ & VU & Poaceae \\
\hline Trifolium repens L. var. repens & - & $\mathrm{R}$ & VU & Fabaceae \\
\hline Trigonella spinosa L. & - & $\mathrm{R}$ & $\mathrm{nl}$ & Fabaceae \\
\hline Tripleurospermum rosellum Hayek & - & $\mathrm{R}$ & VU & Asteraceae \\
\hline Verbascum cheiranthifolium Boiss & - & $\mathrm{R}$ & VU & Scrophulariacea \\
\hline Erodium absinthoides WILLD & LC & $\mathrm{K}$ & EN & Geraniaceae \\
\hline Astragalus kochakii Aytaç \&H.Duman & VU & $\mathrm{nl}$ & VU & Fabaceae \\
\hline Bromus tomentellus Boiss. & - & $\mathrm{nl}$ & $\mathrm{nl}$ & Poaceae \\
\hline Juniperus oxycedrus L. & - & $\mathrm{nl}$ & VU & Cupressaceae \\
\hline Polygala pruinosa Boiss. & - & $\mathrm{nl}$ & $\mathrm{nl}$ & Polygalaceae \\
\hline
\end{tabular}

1980 yılında belirlenen IUCN tehdit kategorileri ve 2013 Endemik bitkiler listesi; Ex: Tükenmiş EW: Doğada tükenmiş CR: Çok tehlikede EN: Tehlikede VU: Zarar görebilir LR: Az tehdit altında DD: Veri yetersiz NE: Değerlendirilmeyen.

Characteristics of endemic plants in 2013 according to UICN danger categories, determined in 1980. Ex: Extinct EW:Extinct in the Wild CR:Critically Endangered EN: Endangered VU: Vulnerable LR: Least Threatened DD: Data Deficient NE: Not Evaluated

http://www.iucnredlist.org/ IUCN Kırmızı Listesi tehdit Kategorileri:LC: Asgari endişe,NT:Neredeyse tehdit altında VU: Hassas EN: Tehlikede CR: Kritik Tehlikede EW: Doğal ortamında tükenmiş EX: Tükenmiş

http://www.iucnredlist.org/ The IUCN Red List of Threatened Species: LC: Least Concern NT: Near Threatened VU:Vulnerable EN:Endangered CR:Critically Endangered EW: Extinct in the Wild EX:Extinct 


\section{Kaynaklar}

Akgül,G.,Pınar, N.M., Sarıtaş,G., Kılıçkaya, N., Kocaman, K., 2014. Batı Toroslara Özgü Tehlike Altına Olan Bir Tür: Globularia davisiana. 22.Ulusal Biyoloji Kongresi. 23-27 Haziran 2014. Eskişehir s. 1007

Altın, M., Gökkuş, A., Koç, A., 2011. Çayır ve Mera Yönetimi. Cilt 1. Genel İlkeler. T.C. Tarım ve Köyişleri Bakanlığı Tarımsal Üretim ve Geliştirme Genel Müdürlüğü, 376. Ankara. 2011

Anonim, 1999. Ulusal Biyolojik Çeşitlilik Stratejisi ve Eylem Planı. T.C. Çevre ve Orman Bakanlığı, Doğa Koruma ve Milli Parklar Genel Müdürlüğü. Doğa Koruma Dairesi Başkanlığı. Ankara 2008.

Anonim, 2013. Version 2013.1. www.iucnredlist.org. Downloaded on 13 November, 2013.

Anonim,2011.www.tuik.gov.tr.

Anonim 2013. http://www.orman.ktu.edu.tr/om/ abds/obotanigi/ders_notu/Bitkisel_Biyocesitlk. pdf.

Atalay, İ. 2002. Türkiye'nin Ekolojik Bölgeleri. Orman Bakanlığı Yayınları, Yayın No:163, ISBN 9758273-4-8, İzmir.

Avcı M., 2005. Çeşitlilik ve Endemizm Açısından Türkiye'nin Bitki Örtüsü. İstanbul Üniversitesi Edebiyat Fakültesi Coğrafya Dergisi, 13, 27-55.

Aygün C., Kara İ, Sever A. L., Erdoğdu İ. ve Atalay A.K. 2013. Eskişehir Meralarının Biyolojik Çeşitliliğe Katkısı. III. Su ve Biyolojik Çeşitlilik Sempozyumu. 22-23 Mayıs 2013 Marmaris. s233-241.

Barthlott, W., Biedinger, N., Braun, G., Feig, F., Kier, G. and Mutke, J. (1999). Terminological and methodological aspects of the mapping and analysis of global biodiversity. Acta Botanica Fennica, 162, 103-110

Brown J.R., Thorpe, J., 2008. Climate range and change and rangelands: responding rationally to uncertainly. Rengelands, 30(3):3-6

Davis, P H. 1988. Flora of Turkey and the East Aegean Islands -University press, Edingburg

Demirci A., 2011. Türkiye'de Odun Dışı Orman Ürünleri Üretimi Konusunda Sorunlar ve Çözüm Önerileri. $2^{\text {nd }}$ International Non-Wood Forest Products Symposium 8-10 September 2011 - Isparta/Turkey,362.

Ehrlich P. R., Wilson, E. O., 1991.Biodiversity studies: science and policy. Science 253: 758-762

Ekim T., Koyuncu M., Vural M., Duman H., Aytaç Z. ve Adıgüzel N., 2000. Türkiye Bitkileri Kırmızı Kitabı. Eğrelti ve Tohumlu Bitkiler. Ankara: Barışcan Ofset. s 1-96
Erik S., Tarikahya, B., 2004. Türkiye Florası Uzerine. Kebikeç (İnsan Bilimleri için Kaynak Araştırmaları Dergisi), 17, 139-163

Gökkuş A., Koç A., Çomaklı B., 1995. Çayır-mera uygulama kılavuzu. Atatürk Üniversitesi Ziraat Fakültesi No: 142, Erzurum139.

GLCCD. Global Land Cover Characteristics Database. 2000. Version 1.2. Available at: http://edcdaac.usgs.gov/ glcc/glcc.html

Griffin G.F., 1989. An enhanced Wheel-Point Method for assessing cover, structure and heterogeneity in plant communities. J. Range Manage., 42,79-81.

Işık K., 1999, Çevre Sorunları Biyolojik Çeşitlilik ve Orman Gen Kaynaklarımız, İstanbul. 197 ss.

Koç A. and Çakal Ş., 2004. Comparison of some rangeland canopy coverage methods, International Soil Congress Natural Resource Management for Sustaiable Development, 710 June, Erzurum, Türkiye, s41-45

Loveland, T. R., Reed, B. C., Brown, J. F., Ohlen, D. O ., Zhu, Z., Yang, L., Merchant, J. W., 2000. Development of a global land cover characteristics database and IGBP DISCover from 1-km AVHRRdata. Int. J. Rem. Sens., 21(2000) 1303-1330

Mayers, N., Andrew, H. K., 2000. The biotic crisis and the future of evolution. Proceedings of the National Academy of Sciences. 98: 53895392.

Tidmarsh, C.E.M., and C.M. Havenga., 1955. The wheel-point method of survey and measurement of semi-open grasslands and Karoo vegetation in South Africa. Botanical Survey South Africa, Memoir 29. 49 pp

White, R.P., Murray, S., Rohweder, M. 2000. Pilot Analysis of Global Ecosystems: Grassland Ecosystems. World Resources Institute. 89pp.

Wilson E. O., 1992 The Diversity of Life.Belknap Press, Harvard Univ. Cambridge, MA.

Yıldız H., Avağ A., Mermer A., Ünal E., Urla Ö., Aydoğdu M., Dedeoğlu F., Özaydın K.A., Aydoğmuş O., 2009. Rakım ve Kuraklık İndisi Değerlerine Göre Türkiye'nin Homojen Alanlarının Belirlenmesi. Tarla Bitkileri Merkez Araştırma Enstitüsü Dergisi. Yıl:2009 Cilt: 18 Sayı: 1-2 